Research Article

\title{
Fabrication of Nanoparticle-Stacked 1,1-Diamino-2,2- Dinitroethylene (FOX-7) Microspheres with Increased Thermal Stability
}

\author{
Yuanping Zhang, ${ }^{1}$ Conghua Hou $\mathbb{D}^{1},{ }^{1}$ Xinlei Jia $\mathbb{D}^{D},{ }^{2}$ Jinyu Wang, and Yingxin Tan $\mathbb{D}^{1}$ \\ ${ }^{1}$ School of Environment and Safety Engineering, North University of China, Taiyuan 030051, China \\ ${ }^{2}$ Department of Chemical Engineering and Safety, Binzhou University, Binzhou, Shandong 256600, China \\ Correspondence should be addressed to Conghua Hou; houconghua@163.com and Yingxin Tan; 13934240901@163.com
}

Received 22 January 2019; Revised 15 April 2019; Accepted 24 April 2019; Published 14 May 2019

Guest Editor: Jakub Zdarta

Copyright () 2019 Yuanping Zhang et al. This is an open access article distributed under the Creative Commons Attribution License, which permits unrestricted use, distribution, and reproduction in any medium, provided the original work is properly cited.

\begin{abstract}
Nanoparticle-stacked 1,1-diamino-2,2-dinitroethylene (FOX-7) microspheres were successfully prepared by spray-drying, and rod-shaped FOX-7 was obtained by the solvent/nonsolvent method for comparison. The microstructure features of samples were characterized using scanning electron microscopy (SEM) and powder X-ray diffraction (XRD), and the thermal properties were also investigated by differential scanning calorimetry (DSC). From the SEM analysis, the particle size of the rod-shaped FOX-7 is about $10 \mu \mathrm{m}$, whereas FOX-7 microspheres having a particle size ranging from 1 to $5 \mu \mathrm{m}$ are formed by stacking nanoparticles with size of $100-250 \mathrm{~nm}$. The crystal form of the samples prepared by the two methods did not change. The thermal performance test results showed that the rd-shaped FOX-7 had no significant change compared with the raw FOX-7, while the nanoparticle-stacked FOX-7 microspheres had higher thermal stability.
\end{abstract}

\section{Introduction}

With the development of modern weapons and ammunition, there is an increasing demand for the performance of explosives, from the pursuit of high-energy elemental explosives to the high-energy-insensitive new explosives. Therefore, many researchers are committed to developing more powerful, safer, and more environmentally friendly energy materials. 1,1-Diamino-2,2-dinitroethylene, called FOX-7 or DADNE, is a high-energy-insensitive explosive due to the molecular structure of hydrogen bonds within and between molecules [1]. It has aroused the interest of scientific researchers since it was developed in 1998 [2]. A large number of previous studies have shown that FOX-7 has excellent comprehensive performance such as low impact sensitivity and friction sensitivity, high energy density, and detonation velocity and is considered as a substitute for RDX used in the military industry [3-7].

Since energetic materials are metastable materials, nanocrystallization can effectively improve the mechanical sensitivity and reaction rate, thereby improving the safety, energy output level, and damage capacity of the explosive [8-10]. Therefore, more and more researchers are devoting themselves to the preparation of nanoexplosives such as 2,4,6,8,10,12-hexanitro-2,4,6,8,10,12-hexaazawurtzitane (CL-20) $[11,12]$, 1,3,5,7-tetranitro-1,3,5,7-tetrazocane (HMX) [13, 14], 1,3,5-trinitro-1,3,5-triazinane (RDX) [15], 3-nitro-1,2,4-triazol-3-one (NTO) [16], and 2,6-diamino3,5-dinitropyrazine-1-oxide (LLM-105) [17] by various methods. Of course, nanosized FOX-7 was also included. In 2010, FOX-7 quasi-three-dimensional (3D) grids of onedimensional nanostructures were synthesized via a sprayfreeze-drying technique by Huang et al. [18]. The results showed that the reduction in the average particle size of the FOX-7 grid structure leads to lower decomposition temperature and higher decomposition rate. Cai et al. [19] prepared a novel FOX-7 nanocrystal by embedding it in mesoporous carbon FDU-15, which demonstrated that FOX-7 nanocrystal sensitivity was closely related to the thermal stability and mechanical stability of FDU-15. Gao et al. [20] successfully 


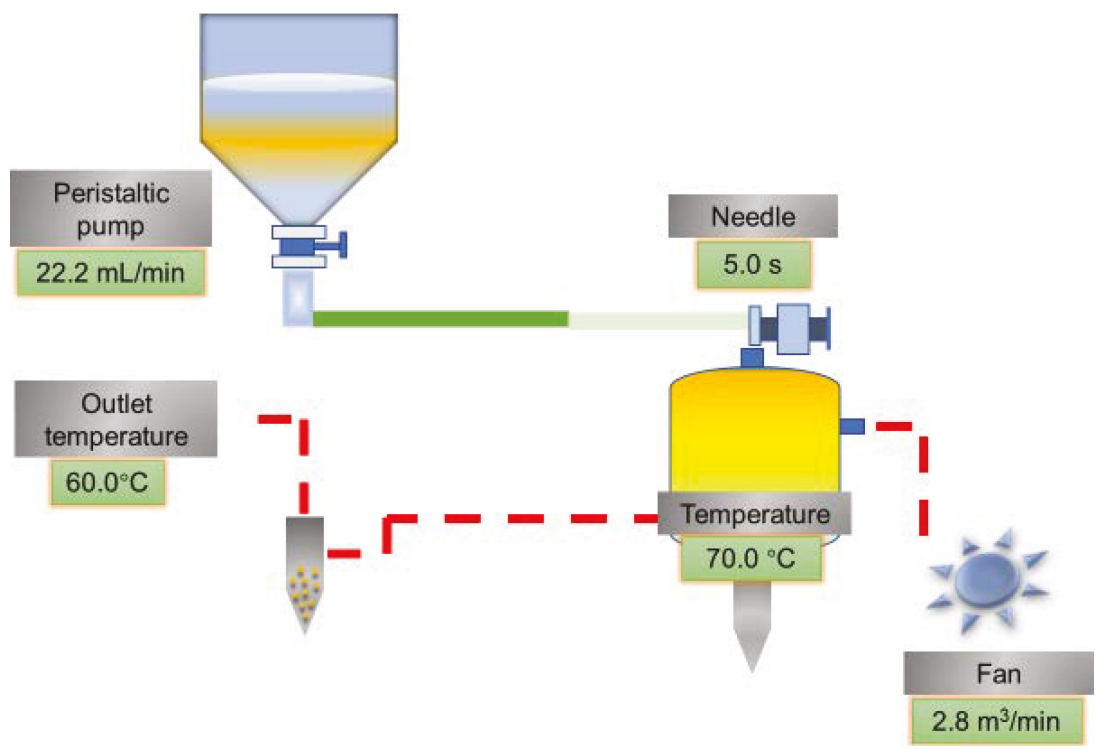

FIGURE 1: Schematic diagram of the spray-drying device.

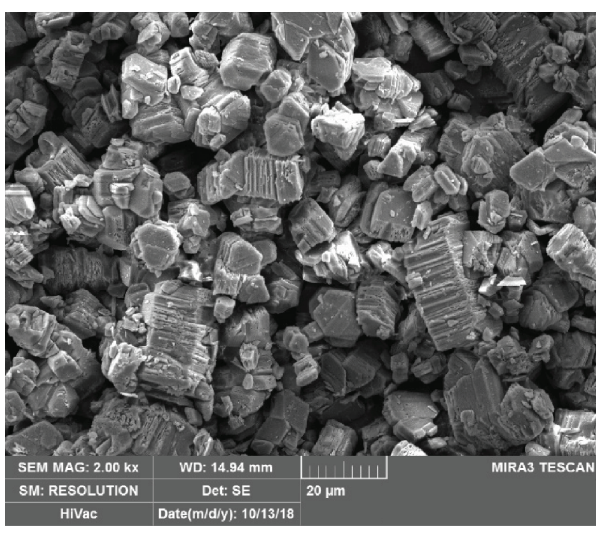

(a)

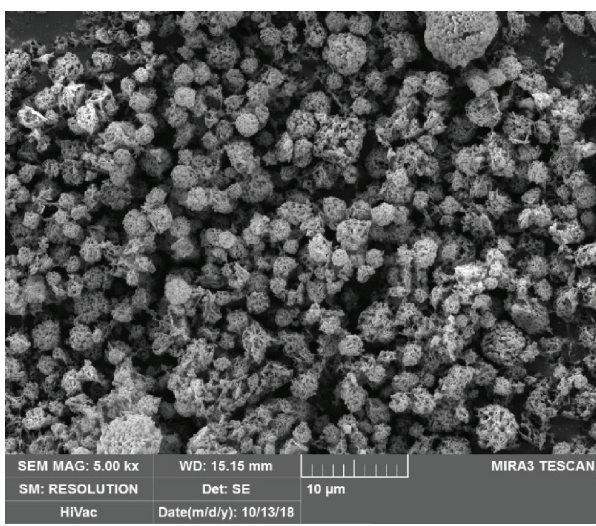

(c)

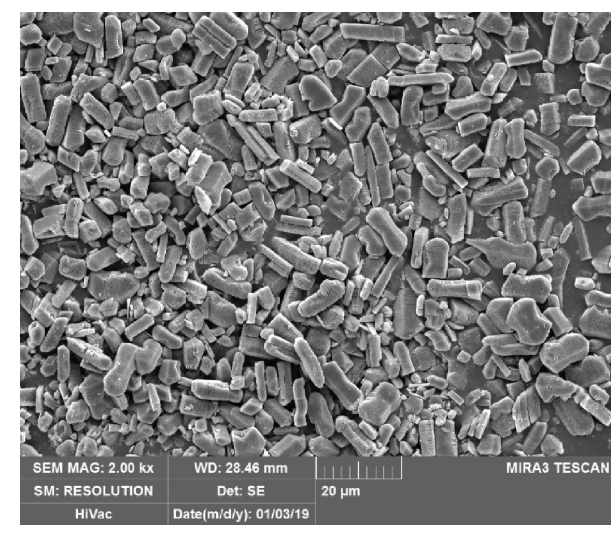

(b)

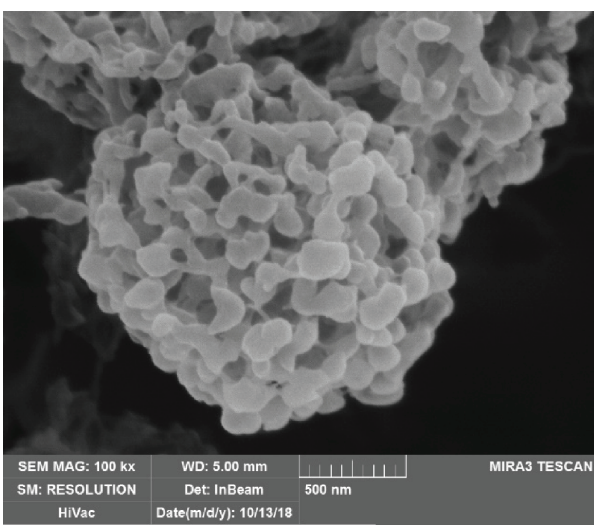

(d)

FIgURE 2: SEM image of raw FOX-7 (a), sample 1 (b), and sample 2 (c, d).

prepared nano-FOX-7 explosive particles by an ultrasonic spray-assisted electrostatic adsorption method in 2014, which has fewer lattice defects and lower internal stress. These explorations implied that the performance of ultrafine FOX-7 has been improved. Therefore, it is of great significance to study the nanosized FOX-7.
Spray-drying is a facile, inexpensive, and scalable technique that has been extensively used in the preparation of microsized spherical material [21]. In this paper, we have prepared nanoparticle-stacked FOX-7 microspheres by spraydrying for the first time. Meanwhile, rod-shaped FOX-7 was obtained by the solvent/nonsolvent method for comparison. 


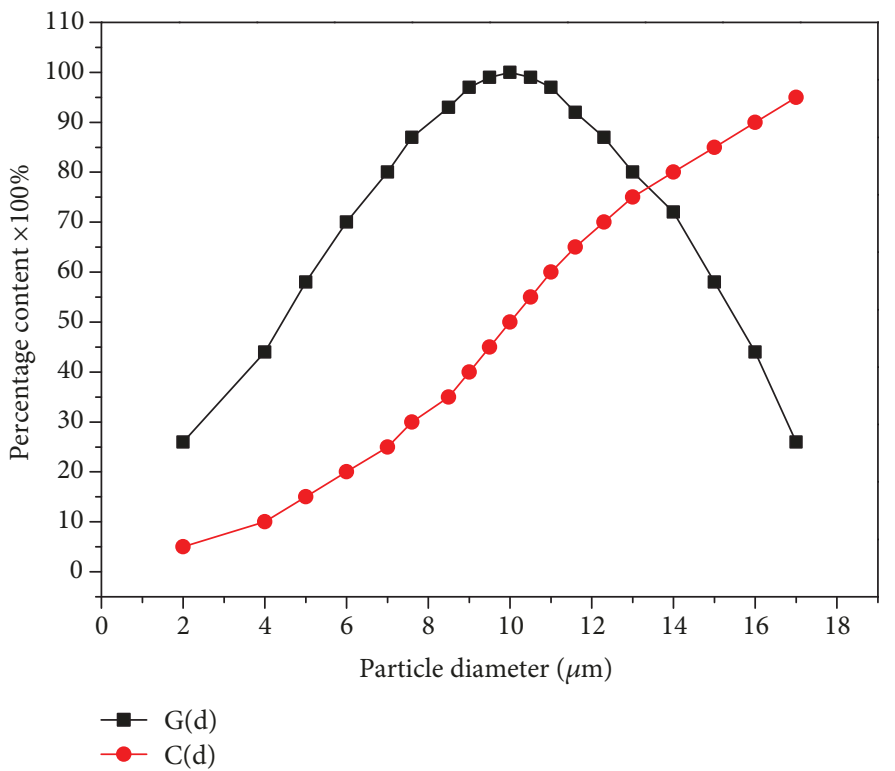

(a)

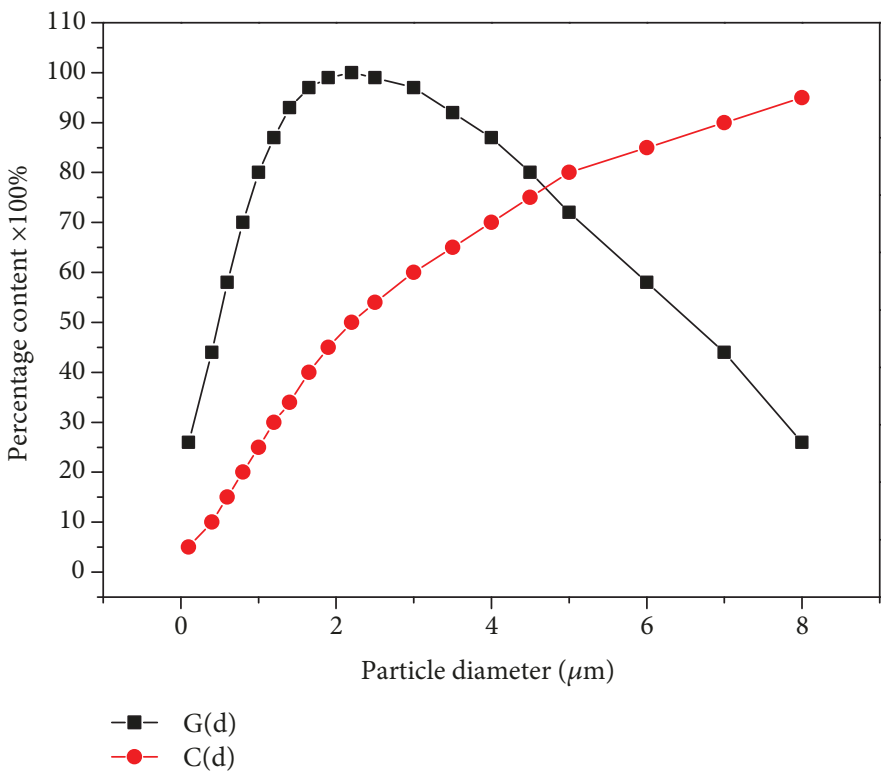

(b)

Figure 3: Particle size and size distribution of sample 1 (a) and sample 2 (b).

The crystal morphology, structure, and thermal properties of samples were systematically investigated in detail.

\section{Materials and Methods}

2.1. Materials. FOX-7, provided by Xi'an Institute of Modern Chemistry, and the purity was higher than 99.5\%. Acetone was obtained by Tianjin Tianda Chemical Co. Ltd. (Tianjin city, P.R. China). Pure water was provided by pure water supply of Taiyuan Iron and Steel Co. Ltd.

\subsection{Sample Preparation}

2.2.1. Preparation of FOX-7 Particles by the Solvent/Nonsolvent Method. About $0.5 \mathrm{~g}$ of raw FOX-7 was dissolved completely in $80 \mathrm{~mL}$ of acetone (solvent) under ultrasonic dispersion at $40^{\circ} \mathrm{C}$ and sprayed to $1000 \mathrm{~mL}$ water (nonsolvent) under stirring at a certain speed using a spraying device to recrystallize the FOX-7 crystal. After suction filtration and freeze-drying, the target sample is obtained, marked as sample 1 .

2.2.2. Preparation of Nanoparticle-Stacked FOX-7 Microspheres by Spray-Dying. In a typical experiment, $0.5 \mathrm{~g}$ FOX-7 and $80 \mathrm{~mL}$ acetone were added to a $100 \mathrm{~mL}$ beaker together. Then, the mixture system was placed in a $45^{\circ} \mathrm{C}$ water bath and stirred until completely dissolved. Next, the solution was pumped into a small spray-drying chamber at a flow rate of $80 \mathrm{~mL} / \mathrm{min}$. The temperatures of inlet and outlet dry gas $\left(\mathrm{N}_{2}\right)$ were set as $70^{\circ} \mathrm{C}$ and $60^{\circ} \mathrm{C}$, respectively. The spray gas 


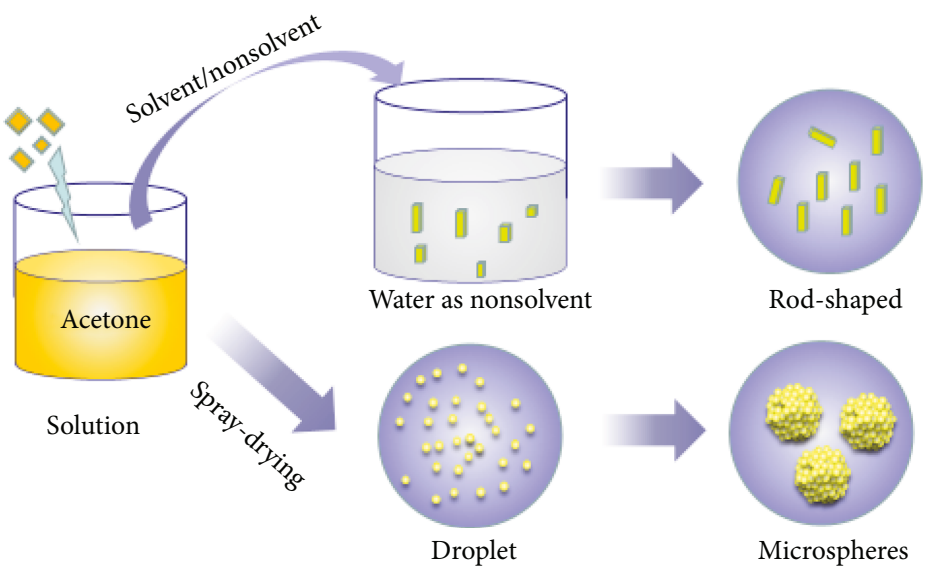

Figure 4: Schematic illustration of the formation of sample 1 and sample 2.

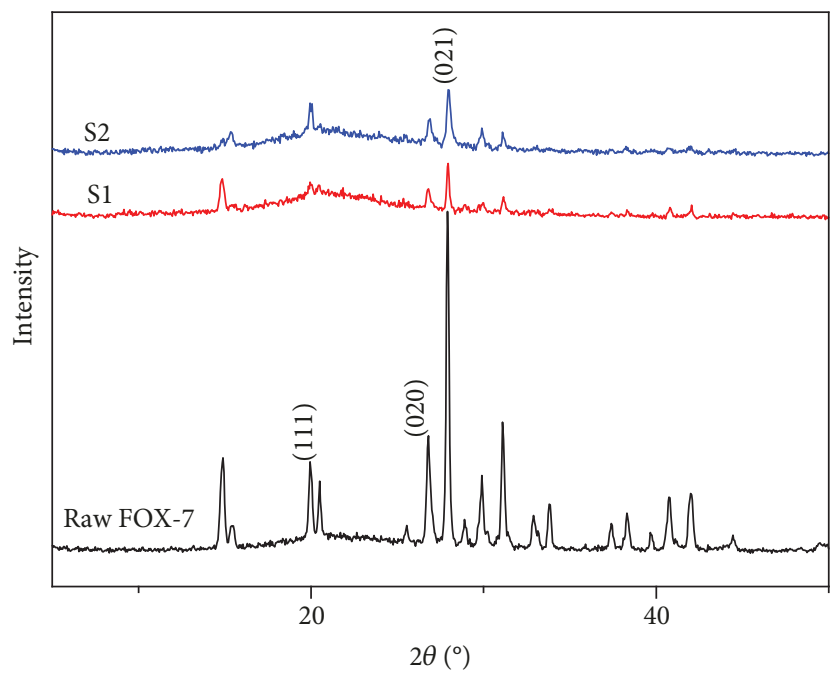

FIgURE 5: XRD patterns of raw FOX-7, sample 1, and sample 2.

flow rate was $2.8 \mathrm{~m}^{3} / \mathrm{min}$. Finally, the products were separated from the drying gas with a cyclone separator and collected in an electrically grounded glass collection vessel. This product is marked as sample 2 . The schematic diagram of the spray-drying device is shown in Figure 1.

2.3. Characterization. The morphology and size distribution of raw FOX-7 and as-prepared FOX-7 particles were examined using a MIRA3 LMH scanning electron microscope (Tescan, Czech Republic). The as-obtained samples were dispersed on conductive carbon adhesive tape to attach to a SEM stub and then gold-coated for SEM investigation. Power $\mathrm{X}$-ray diffraction (Dandong Haoyuan Corporation, Liaoning, China) was used to visualize the changes in the crystal structure of the samples. PXRD patterns were recorded using a Bruker D8 Advance diffractometer at a voltage of $40 \mathrm{kV}$ and a current of $30 \mathrm{~mA}$ using $\mathrm{Cu} \mathrm{K} \alpha$ radiation at $\lambda=1.5418 \AA$. The thermal properties were characterized by DSC Q20P (TA Instruments). The DSC conditions used are as follows: sample mass: $0.7 \mathrm{mg}$; heating rate: $5,10,15$, and $20 \mathrm{~K} / \mathrm{min}$; and nitrogen atmosphere under the pressure of $0.1 \mathrm{MPa}$. The sample size was tested by a QICPIC dynamic particle analyzer (Sympatec Co. Ltd., Germany), and its working environment is $5 \sim 35^{\circ} \mathrm{C}$, the relative humidity is less than $85 \%$, the light source type is $\mathrm{He}-\mathrm{Ne}$ laser, the power is $2.0 \mathrm{~mW}$, and the wavelength is $0.6328 \mu \mathrm{m}$.

\section{Results and Discussion}

3.1. Morphologies of the FOX-7 Typical Microspheres. The morphology of raw FOX-7 and as-prepared FOX-7 particles was observed by SEM, as shown in Figure 2. From Figure 2(a), we can see that the raw FOX-7 has an irregular block and has a distinct layered structure, which is consistent with that described in ref. [1]. The particle size distribution is approximately $20 \mu \mathrm{m}$, and there are cracks on the surface of the crystal. The FOX-7 samples modified by two methods have obviously improved compared with raw materials. It can be seen from Figure 2(b) that the sample 1 prepared by the solvent/nonsolvent method had a rod-like structure and a large particle size of about $10 \mu \mathrm{m}$ and the surface defects of the crystal decrease. The microscopic morphology of FOX-7 prepared by the spray-drying method was the submicrosphere having a significantly reduced particle with the 


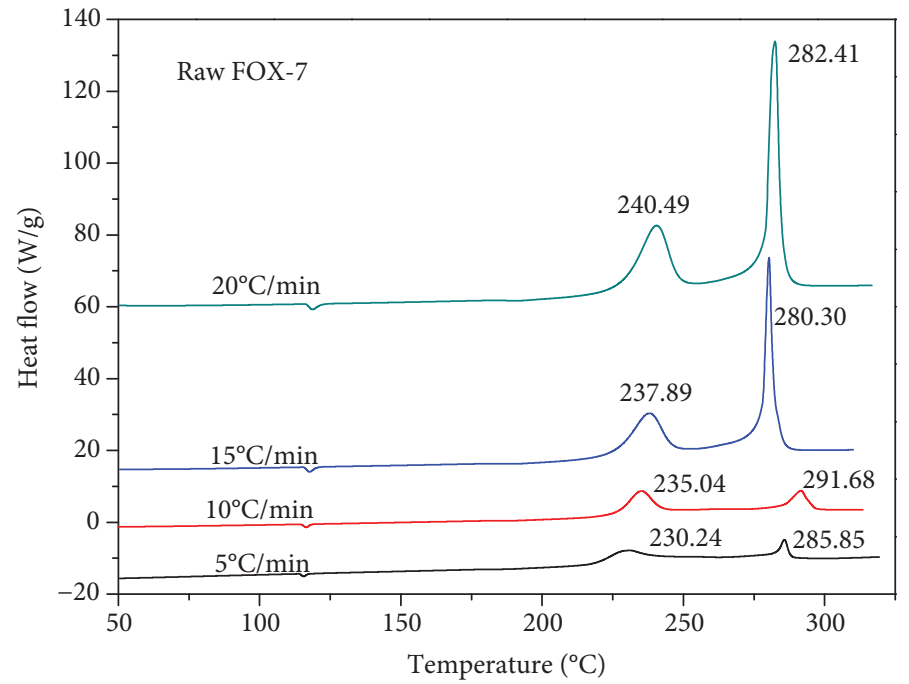

(a)

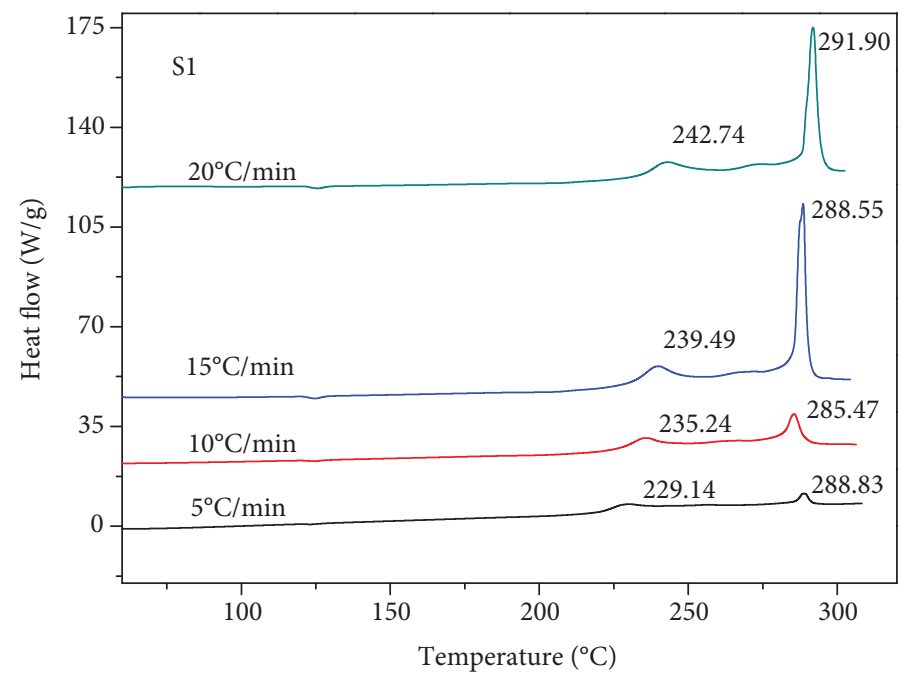

(b)

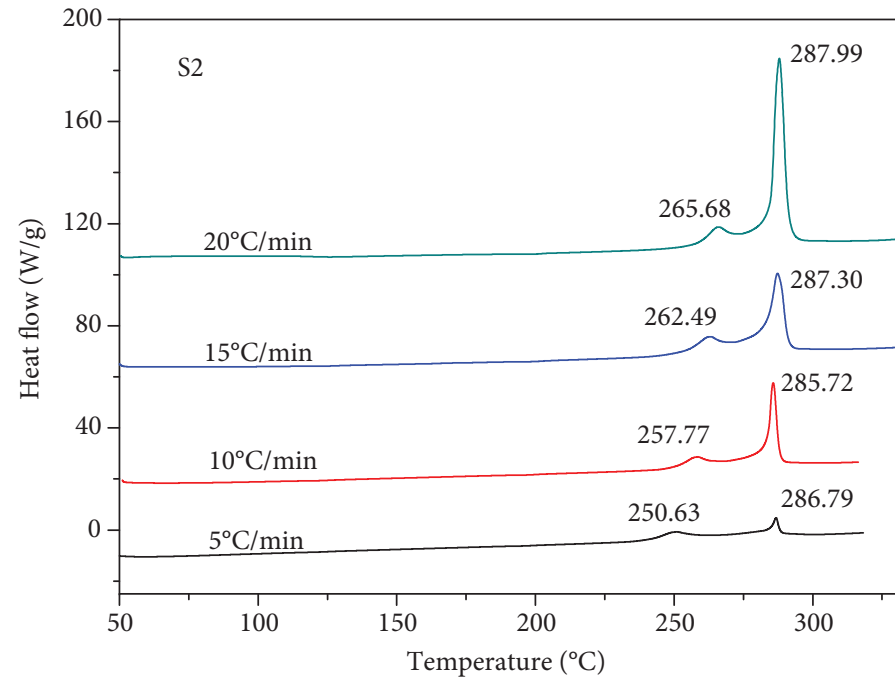

(c)

Figure 6: DSC curves of raw FOX-7 (a), sample 1 (b), and sample 2 (c). 
TABLE 1: Thermal decomposition kinetic parameters of samples.

\begin{tabular}{|c|c|c|c|c|c|}
\hline & \multicolumn{2}{|c|}{ Kissinger } & \multirow{2}{*}{$\begin{array}{c}\text { Ozawa } \\
\mathrm{Ea}(\mathrm{kJ} / \mathrm{mol})\end{array}$} & \multirow{2}{*}{$\begin{array}{c}\text { Starink } \\
\mathrm{Ea}(\mathrm{kJ} / \mathrm{mol})\end{array}$} & \multirow{2}{*}{$\begin{array}{l}\text { Mean activation } \\
\text { energy }(\mathrm{kJ} / \mathrm{mol})\end{array}$} \\
\hline & $\mathrm{Ea}(\mathrm{kJ} / \mathrm{mol})$ & $\lg \mathrm{A}\left(\mathrm{s}^{-1}\right)$ & & & \\
\hline FOX-7 & 285.47 & 29.46 & 293.92 & 286.32 & 288.57 \\
\hline Sample 1 & 211.14 & 18.67 & 219.60 & 211.99 & 214.24 \\
\hline Sample 2 & 206.67 & 17.27 & 215.50 & 207.56 & 209.91 \\
\hline
\end{tabular}

TABLE 2: Thermodynamic property data of the samples.

\begin{tabular}{lccccc}
\hline & $T_{b}\left({ }^{\circ} \mathrm{C}\right)$ & $T_{\mathrm{p}}\left({ }^{\circ} \mathrm{C}\right)$ & $\Delta S^{\ddagger}(\mathrm{J} / \mathrm{mol})$ & $\Delta H^{\ddagger}(\mathrm{kJ} / \mathrm{mol})$ & $\Delta G^{\neq}(\mathrm{kJ} / \mathrm{mol})$ \\
\hline FOX-7 & 223.24 & 221.79 & 306.53 & 281.36 & 129.64 \\
Sample 1 & 221.77 & 220.34 & 100.00 & 207.04 & 157.69 \\
Sample 2 & 241.88 & 240.18 & 72.87 & 202.40 & 165.00 \\
\hline
\end{tabular}

grain diameter ranging from $1 \mu \mathrm{m}$ to $5 \mu \mathrm{m}$. The particle distribution curves of the samples are shown in Figure 3. It is clear that the median particle size of sample 1 and sample 2 are 10 and $2 \mu \mathrm{m}$, respectively, confirming the results of the SEM test.

It can be clearly observed from Figure 2(d) that the FOX-7 microspheres are solid microspheres which are formed by stacking small nanoparticles with the grain diameter ranging from $100 \mathrm{~nm}$ to $250 \mathrm{~nm}$. It was found that large crystals were obtained after rapid self-assembly. The formation process is explained as follows: the FOX-7 solution is formed into a mist-like droplet by an atomizer and then enters into a drying chamber of a low-pressure hot nitrogen gas, and the droplets are moved to the collecting device under hot air and pressure conditions. As the solvent evaporates rapidly, the tiny droplets become a supersaturated solution. Then, the nanoparticles are formed by rapid nucleation and agglomeration to form microspheres. The schematic illustration of the formation process of sample 1 and sample 2 are shown in Figure 4.

3.2. Crystal Structure of Samples. XRD measurements were carried out to identify the crystalline phase. Figure 5 shows the XRD patterns of raw FOX-7 and samples prepared. The characteristic diffraction peaks ( $\left.\begin{array}{lll}1 & 1 & 1\end{array}\right),\left(\begin{array}{lll}0 & 2 & 0\end{array}\right)$, and $\left(\begin{array}{lll}0 & 2 & 1\end{array}\right)$ of raw FOX-7 appeared at $2 \theta$ of $19.846^{\circ}, 26.604^{\circ}$, and $27.74^{\circ}$, respectively, as marked in Figure 5 . It can be also seen that the characteristic diffraction peaks of sample 1 and sample 2 are consistent with those of the raw FOX-7, indicating that during the two processes of solvent/nonsolvent and spray-drying, the crystal structure did not change and good crystallinity was maintained. The peak intensity of the refined samples becomes weaker due to the decrease in grain size and serious X-ray dispersion.

Based on the Debye-Scherrer equation and diffraction peak at $2 \theta=26.604^{\circ}$, the average crystalline size was calculated as $26.55 \mathrm{~nm}$.

$$
D=\frac{k \lambda}{\beta \cos \theta},
$$

where $D$ is the grain diameter perpendicular to the crystal plane $(\mathrm{nm}), k$ is the Scherrer constant (usually 0.89 ), $\lambda$ is the incident $\mathrm{X}$-ray wavelength $(\lambda(\mathrm{Cu})=0.154059 \mathrm{~nm}), \beta$ is the peak width of the diffraction peak at half max (rad), and $\theta$ is the angle of the diffraction peak.

3.3. Thermal Performance. Thermal stability is a key performance in the field of energetic materials. The thermal performance of raw FOX-7, sample 1, and sample 2 as-prepared were tested using differential scanning calorimetry. The DSC curves of raw FOX-7, sample 1, and sample 2 with the linear heating rate of $5,10,15$, and $20^{\circ} \mathrm{C} / \mathrm{min}$ were recorded in a nitrogen atmosphere (Figure 6). As can be seen from Figure 6, there are two decomposition exothermic peaks in the DSC curves of raw FOX-7 and FOX-7 as-obtained, indicating that the decomposition process can be divided into two stages. The first stage is the low-temperature decomposition stage, in which two amino hydrogens and one nitro oxygen are removed from the adjacent FOX-7 molecule to form a water molecule, accompanied by the condensation reaction of carbon-carbon double bonds. The second stage is the hightemperature decomposition stage, mainly due to the fracture of carbon skeleton in the FOX-7 molecule [7]. Under the same heating rate, the first decomposition peak temperature of the sample prepared by the solvent/nonsolvent method was delayed by $1-2^{\circ} \mathrm{C}$ from the peak temperature of the raw material, and that of sample 2 obtained via spray-drying was postponed at about $20^{\circ} \mathrm{C}$. It shows that as the particle size decreases, the peak temperature of the low-temperature decomposition is postponed, which is similar to the literature research results [18-20]. This is because the FOX-7 particles are small and the internal stress is also small, and the internal stress generated by the resulting product is insufficient to cause the FOX-7 particles to rupture to form smaller particles [22]. Therefore, the particles begin to decompose when the temperature rises to a certain extent, resulting in a delay in the exothermic peak of the first stage. At different heating rates, the exothermic peak of sample 2 was $285 \sim 288^{\circ} \mathrm{C}$, and the high-low-temperature liberation heat range was significantly smaller than that of sample 1 and raw materials, indicating that sample 2 was more concentrated in heat release and had higher energy release efficiency. The second decomposition peak temperature of FOX-7 at different heating rates did not move regularly, which was related to the specific thermal decomposition characteristics of FOX-7. It may be due to 


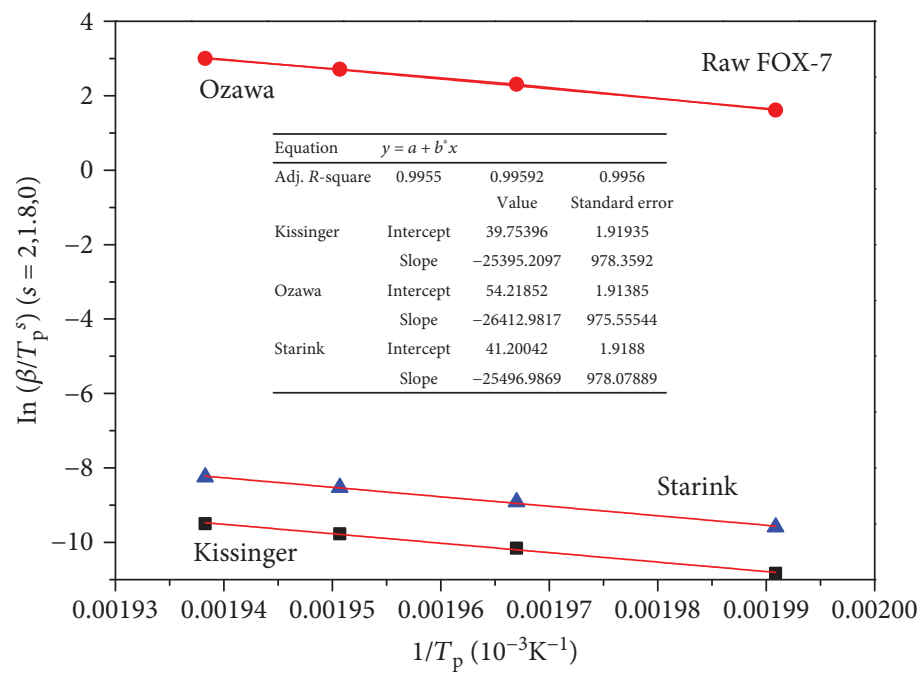

(a)

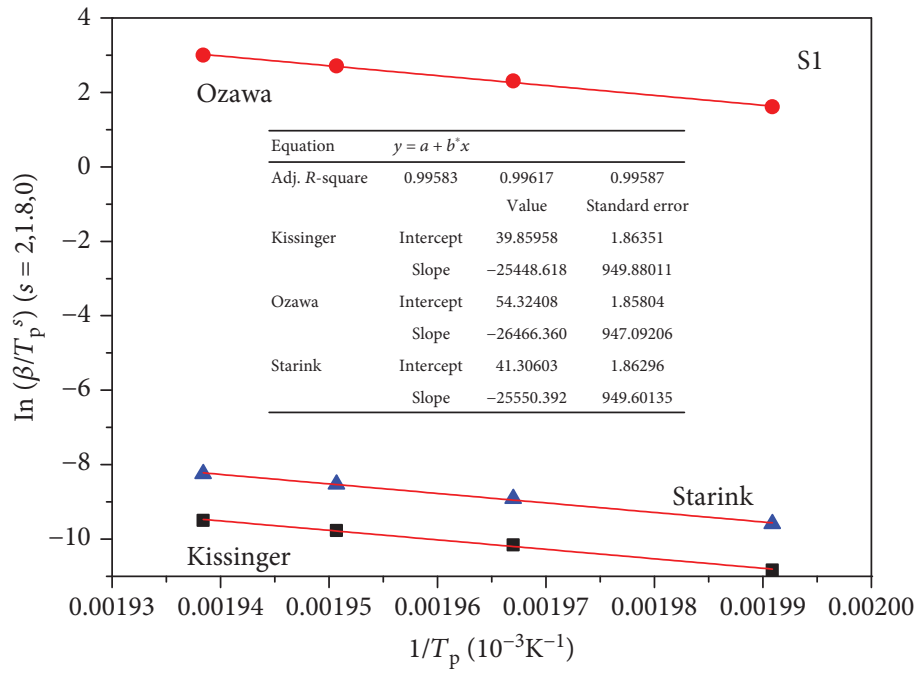

(b)

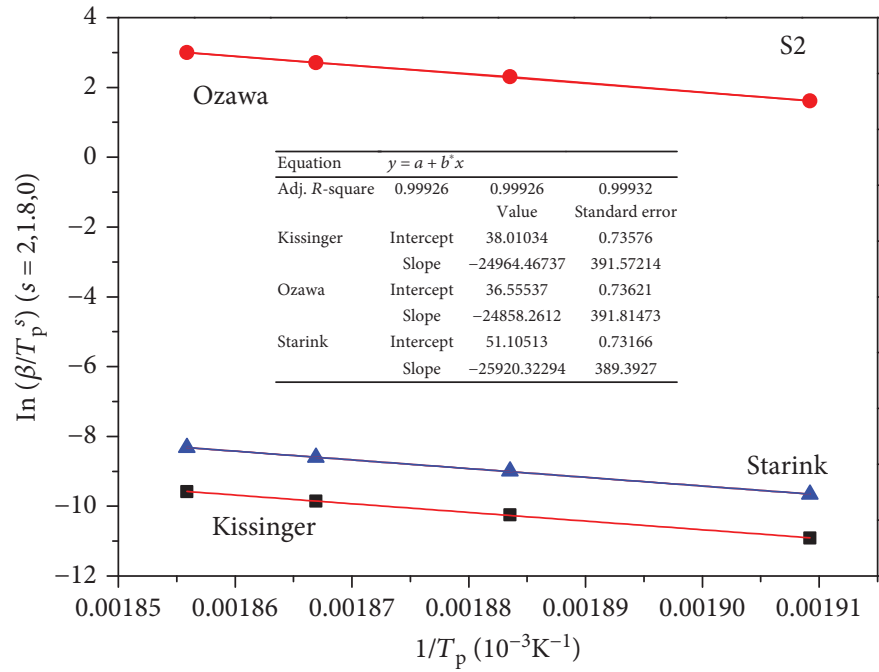

(c)

FIGURE 7: Reaction kinetics fit curve of the raw material FOX-7 (a) and samples 1 (b) and 2 (c) by the Kissinger method, Ozawa method, and Starink method. 
mechanical changes related to thermal redistribution from the second peak to the first peak, or to the thermal runaway, where the sample temperature was much higher than the measured temperature.

Furthermore, in order to evaluate its thermal performance, the kinetic and thermodynamic parameters were further performed. Kissinger's method [23], Flynn-WallOzawa's method [24], and Starink's method [25] were enlisted to calculate the apparent activation energy $\left(E_{\mathrm{a}}\right)$ and preexponential factor $(A)$. The calculation process is consistent with that in ref. [26]. The data are shown in Table 1. The critical temperature of thermal explosion $\left(T_{b}\right)$, the value of the peak temperature corresponding to $\beta \rightarrow 0\left(T_{\mathrm{P} 0}\right)$, entropy of activation $\left(\Delta S^{\ddagger}\right)$, enthalpy of activation $\left(\Delta H^{\ddagger}\right)$, and free energy of activation $\left(\Delta G^{\ddagger}\right)$ of the samples were then calculated based on formulas 2-6 [27] and are listed in Table 2.

$$
\begin{aligned}
T_{\mathrm{p}} & =T_{\mathrm{p} 0}+b \beta_{i}+c \beta_{i}^{2}+d \beta_{i}^{3}, \\
T_{\mathrm{b}} & =\frac{E_{\mathrm{a}}-\sqrt{E_{\mathrm{a}}^{2}-4 R E_{\mathrm{a}} T_{\mathrm{p} 0}}}{2 R}, \\
\Delta H^{\neq} & =E_{k}-R T_{\mathrm{p} 0} \\
A_{k} \exp \left(\frac{E_{k}}{R T}\right) & =\frac{k_{\mathrm{B}} T_{\mathrm{p} 0}}{h} \exp \left(-\frac{\Delta G^{\neq}}{R T_{\mathrm{p} 0}}\right), \\
\Delta G^{\neq} & =\Delta H^{\neq}-T_{\mathrm{p} 0} \Delta S^{\neq},
\end{aligned}
$$

where $\beta_{i}$ is the heating rate in ${ }^{\circ} \mathrm{C} / \mathrm{min} ; T_{\mathrm{p}}$ is the peak temperature in the DSC trace at $\beta_{i}$ in $\mathrm{K} ; R$ is the universal gas constant $\left(8.318 \mathrm{~J} \mathrm{~K}^{-1} \mathrm{~mol}^{-1}\right) ; A$ is the preexponential factor in $\mathrm{s}^{-1} ; E_{\mathrm{a}}$ is the apparent activation energy in $\mathrm{kJ} \mathrm{mol}^{-1} ; k$ is the rate constant in $\mathrm{s}^{-1} ; T_{\mathrm{p} 0}$ is the peak temperature when $\beta_{i}$ is zero in $\mathrm{K} ; b, c$, and $d$ are constants; $T_{b}$ is the critical explosion temperature in ${ }^{\circ} \mathrm{C} ; k_{\mathrm{B}}$ is Boltzmann constant $\left(1.381 \times 10^{-23} \mathrm{~J} \mathrm{~K}^{-1}\right)$, $h$ is the Plank constant $\left(6.626 \times 10^{-34} \mathrm{~J} \bullet \mathrm{s}\right) ; \Delta G^{\neq}$is the free energy of activation in $\mathrm{kJ} \mathrm{mol}^{-1} ; \Delta H^{\ddagger}$ is the enthalpy of activation in $\mathrm{kJ} \mathrm{mol}^{-1}$; and $\Delta S^{\neq}$is the entropy of activation in $\mathrm{J} \mathrm{mol}^{-1}$.

The apparent activation energies of samples 1 and 2 were reduced by 74.33 and $78.66 \mathrm{~kJ} / \mathrm{mol}$, respectively, compared to the raw material FOX-7. Figure 7 shows the reaction kinetic fit curve of the raw material FOX-7 and samples 1 and 2 by three methods. It can be found that the linear correlation coefficients of the fitting straight line are greater than 0.99 , implying that the measured data is accurate and reliable. The thermal explosion critical temperature of sample 1 was lowered by $1.47^{\circ} \mathrm{C}$, while that of sample 2 was increased by $18.64^{\circ} \mathrm{C}$, which can be concluded that microsphere FOX-7 had better thermal stability.

\section{Conclusion}

Herein, the rod-shaped FOX-7 and microspheres FOX-7 were successfully prepared by the solvent/nonsolvent method and spray-drying method, respectively. Surprisingly, microspheres FOX-7 having a particle size ranging from 1 to
$5 \mu \mathrm{m}$ are formed by stacking nanoparticles with size of 100$250 \mathrm{~nm}$, which is obviously smaller than the raw material. In the two processes of preparing samples, the FOX-7 maintains the $\alpha$-form. From the results of thermal analysis, the similar decomposition process indicates that sample 2 keeps better thermal stability, which may be highly desirable for microenergetic systems.

\section{Data Availability}

The data used to support the findings of this study are available from the corresponding author upon request.

\section{Conflicts of Interest}

The authors declare that there is no conflict of interest regarding the publication of this paper.

\section{Acknowledgments}

This research work was financially supported by the Graduate Education Innovation Project in Shanxi Province (2018BY089) and the 15th Graduate Science and Technology Project of North University of China (20181568).

\section{References}

[1] U. Bemm and H. Östmark, "1,1-Diamino-2,2-dinitroethylene: a novel energetic material with infinite layers in two dimensions," Acta Crystallographica Section C Crystal Structure Communications, vol. 54, no. 12, pp. 1997-1999, 1998.

[2] N. V. Latypov, J. Bergman, A. Langlet, U. Wellmar, and U. Bemm, "Synthesis and reactions of 1,1-diamino-2,2-dinitroethylene," Tetrahedron, vol. 54, no. 38, pp. 11525-11536, 1998.

[3] H. Bergman, H. Östmark, A. Pettersson, M. L. Pettersson, U. Behm, and M. Hihkio, "Some initial properties and thermal stability of FOX-7," in Insensitive Munitions and Energetic Materials Symposium, pp. 346-351, National Defense Industrial Association, Tampa, FL, USA, 1999.

[4] H. Ostmark, H. Bergman, U. Bemm et al., "2,2-dinitro-ethene1,1-diamine (FOX-7)-properties, analysis and scale-up," in Energetic materials-Ignition, combustion and detonation, p. 26-1, Karlsruhe, Germany, 2001.

[5] A. K. Burnham, R. K. Weese, R. Wang, Q. M. Kwok, and D. G. Jones, "Thermal properties of FOX-7," in 36th International Annual Conference of ICT \& 32nd International Pyrotechnics Seminar, Karlsruhe, Germany, 2005.

[6] Q. B. Fu, Y. J. Shu, and Y. G. Huang, "Thermal decomposition mechanism of FOX-7," Journal of Solid Rocket Technology, vol. 33, no. 1, pp. 77-80, 2010.

[7] D. E. Taylor, F. Rob, B. M. Rice, R. Podeszwa, and K. Szalewicz, "A molecular dynamics study of 1,1-diamino-2,2-dinitroethylene (FOX-7) crystal using a symmetry adapted perturbation theory-based intermolecular force field," Physical Chemistry Chemical Physics, vol. 13, no. 37, pp. 16629-16636, 2011.

[8] J. E. Um, T. Yeo, W. Choi, J. S. Chae, H. S. Kim, and W. J. Kim, "Enhanced energy release from homogeneous carbon nanotube-energetic material composites," Science of Advanced Materials, vol. 8, no. 1, pp. 164-170, 2016. 
[9] N. Zohari, M. H. Keshavarz, and S. A. Seyedsadjadi, "The advantages and shortcomings of using nano-sized energetic materials," Central European Journal of Energetic Materials, vol. 10, no. 1, pp. 135-147, 2013.

[10] S. B. Kim, K. J. Kim, M. H. Cho, J. H. Kim, K. T. Kim, and S. H. Kim, "Micro- and nanoscale energetic materials as effective heat energy sources for enhanced gas generators," ACS Applied Materials \& Interfaces, vol. 8, no. 14, pp. 9405-9412, 2016.

[11] Y. Bayat, M. Zarandi, M. A. Zarei, R. Soleyman, and V. Zeynali, "A novel approach for preparation of CL-20 nanoparticles by microemulsion method," Journal of Molecular Liquids, vol. 193, pp. 83-86, 2014.

[12] D. Wang, B. Gao, G. Yang, F. Nie, and H. Huang, "Preparation of Cl-20 explosive nanoparticles and their thermal decomposition property," Journal of Nanomaterials, vol. 2016, Article ID 5462097, 7 pages, 2016.

[13] R. Kumar, P. F. Siril, and P. Soni, "Optimized synthesis of HMX nanoparticles using antisolvent precipitation method," Journal of Energetic Materials, vol. 33, no. 4, pp. 277-287, 2015.

[14] X. Jia, J. Wang, C. Hou, and Y. Tan, "Green preparation, spheroidal, and superior property of nano-1,3,5,7-tetranittro1,3,5,7-tetrazocane," Journal of Nanomaterials, vol. 2018, Article ID 5839037, 8 pages, 2018.

[15] F. Pessina, F. Schnell, and D. Spitzer, "Tunable continuous production of RDX from microns to nanoscale using polymeric additives," Chemical Engineering Journal, vol. 291, pp. 12-19, 2016.

[16] G. Yang, F. Nie, J. Li, Q. Guo, and Z. Qiao, "Preparation and characterization of nano-NTO explosive," Journal of Energetic Materials, vol. 25, no. 1, pp. 35-47, 2007.

[17] C. Huang, J. Liu, L. Ding, D. Wang, Z. Yang, and F. Nie, "Facile fabrication of nanoparticles stacked 2,6-diamino-3,5-dinitropyrazine-1-oxide (LLM-105) sub-microspheres via electrospray deposition," Propellants, Explosives, Pyrotechnics, vol. 43, no. 2, pp. 188-193, 2018.

[18] B. Huang, Z. Qiao, F. Nie et al., "Fabrication of FOX-7 quasithree-dimensional grids of one-dimensional nanostructures via a spray freeze-drying technique and size-dependence of thermal properties," Journal of Hazardous Materials, vol. 184, no. 1-3, pp. 561-566, 2010.

[19] H. Cai, L. Tian, B. Huang, G. Yang, D. Guan, and H. Huang, "1,1-Diamino-2,2-dintroethene (FOX-7) nanocrystals embedded in mesoporous carbon FDU-15," Microporous and Mesoporous Materials, vol. 170, pp. 20-25, 2013.

[20] B. Gao, P. Wu, B. Huang et al., "Preparation and characterization of nano-1,1-diamino-2,2-dinitroethene (FOX-7) explosive," New Journal of Chemistry, vol. 38, no. 6, pp. 2334-2341, 2014.

[21] R. Vehring, "Pharmaceutical particle engineering via spray drying," Pharmaceutical Research, vol. 25, no. 5, pp. 9991022, 2008.

[22] E. A. Prodan, "Localization phenomena of topochemical reactions," Journal of Thermal Analysis, vol. 29, no. 5, pp. 941-948, 1984.

[23] H. E. Kissinger, "Reaction kinetics in differential thermal analysis," Analytical Chemistry, vol. 29, no. 11, pp. 1702-1706, 1957.

[24] T. Ozawa, "A new method of analyzing thermogravimetric data," Bulletin of the Chemical Society of Japan, vol. 38, no. 11, pp. 1881-1886, 1965.
[25] P. G. Boswell, "On the calculation of activation energies using a modified Kissinger method," Journal of Thermal Analysis and Calorimetry, vol. 18, no. 2, pp. 353-358, 1980.

[26] X. Li, B. Wu, S. Liu, C. An, and J. Wang, "An insensitive booster explosive: DAAF surface-coated with viton A," Central European Journal of Energetic Materials, vol. 15, no. 3, pp. 445-455, 2018.

[27] Y. Wang, X. Song, D. Song, L. Liang, C. An, and J. Wang, "Synthesis, thermolysis, and sensitivities of HMX/NC energetic nanocomposites," Journal of Hazardous Materials, vol. 312, pp. 73-83, 2016. 


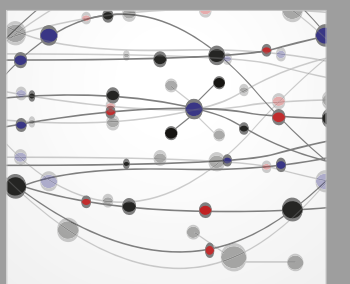

The Scientific World Journal
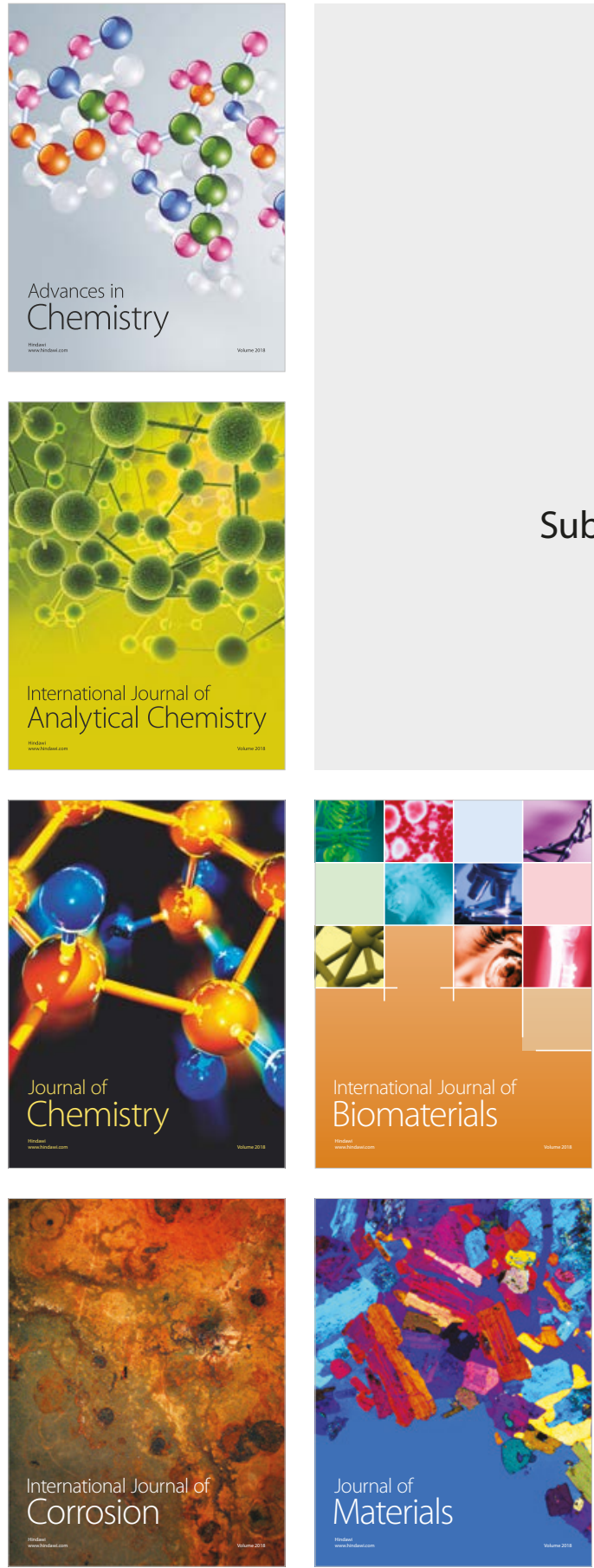

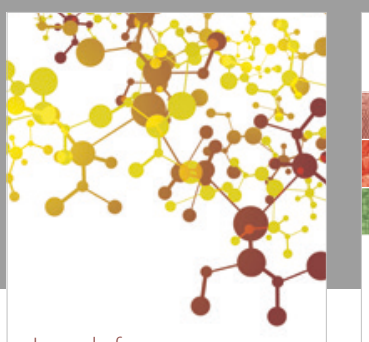

Journal of

Applied Chemistry
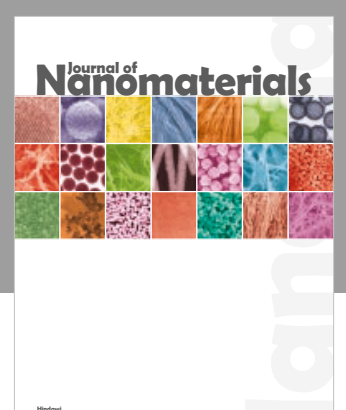

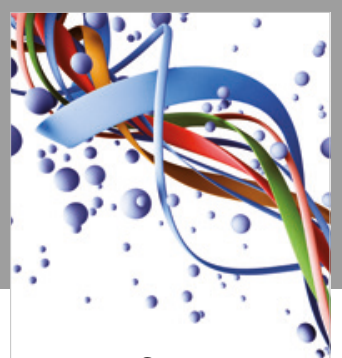

Scientifica

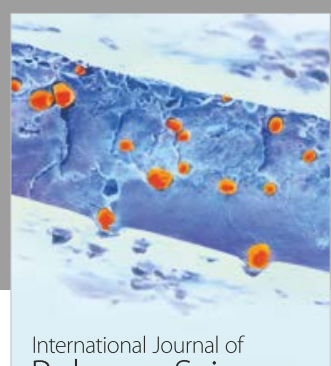

Polymer Science

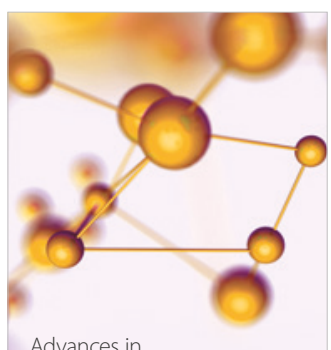

Physical Chemistry
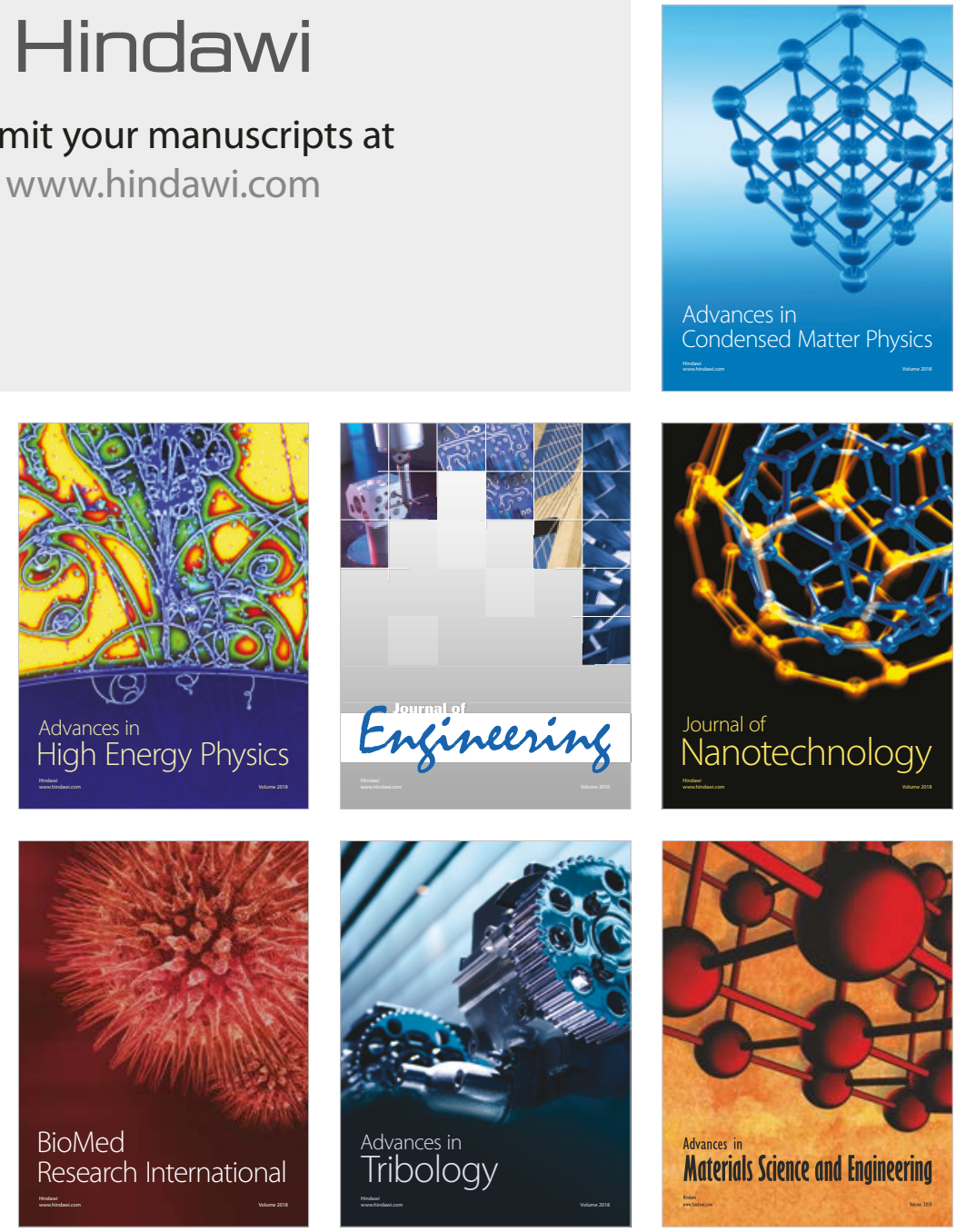